гические методы упрочнения: в 2 т. - М.: Машиностроение, 1995. - Т. 2. - 668 с.

6. Сайфуллин Р.С. Композиционные покрытия и материалы. - М.: Химия.1977. - 272 с.

7. Сафонов В.В., Александров В.А., Шишурин С.А., Азаров А.С. Применение наноматериалов при техническом сервисе автотракторной техники // Вестник Федерального государственного образовательного учреждения высшего профессионального образования Московский государственный агроинженерный университет им. В.П. Горячкина. - 2009. - № 3. - С. 62-66.

8. Сафонов В.В., Шишурин С.А., Годунов Н.Б., Семочкин В.С. Нанокомпозиционные никель-фосфорные покрытия с улучшенными эксплуатационными свойствами // Вестник Саратовского госагроуниверситета им. Н.И. Вавилова. - 2011. - № 12. - С. 56-58.

9. Шишурин С. А., Семочкин В. С., Сафонов В. В., Гурьев А. Е. Структура и физико-механические свойства композиционных гальванохимических покрытий // Вестник АПК Ставрополя. - 2014. - № 3 (15). C. $77-80$.

10. Safonov V.V., Shishurin S.A., Semochkin V.S., Zakharevich A.M. Effect of alumina nanoparticles on the structure and physicochemical properties of chromium coatings // Surface Engineering and Applied Electrochemistry.
2015. T. 51. № 6. С. 517-522.

Сафонов Валентин Владимирович, $\partial-p$ техн. наук, проф., зав. кафедрой «Технический сервис и технология конструкционных материалов», Саратовский государственный аграрный университет имени Н.И. Вавилова. Россия.

Шишурин Сергей Александрович, канд. техн. наук, доцент кафедры «Технический сервис и технология конструкиионных материалов», Саратовский государственный аграрный университет имени Н.И. Вавилова. Россия.

Чумакова Светлана Валентиновна, канд. техн. наук, доцент кафедры «Математика и математическое моделирование», Саратовский государственный аграрный университет имени Н.И. Вавилова. Россия.

Горбушин Павел Александрович, ассистент кафедры «Технический сервис и технология конструкционных материалов», Саратовский государственный аграрный университет имени Н.И. Вавилова. Россия.

410056, г. Саратов, ул. Советская, 60.

Тел.: (8452) 74-96-56.

Ключевые слова: композиционные покрытия; гальванические покрытия; нанодисперные частицы; надежность; степень упрочнения; микротвердость; дислокации; структура материала.

\title{
PHYSICO-MATHEMATICAL MODEL OF THE MECHANISM OF GALVANIC COATINGS BY NANOSCALE MATERIALS
}

Safonov Valentin Vladimirovich, Doctor of Technical Sciences, Professor, Head of the chair "Technical Service and Technology of Structural Materials", Saratov State Agrarian University named after N.I. Vavilov. Russia.

Shishurin Sergey Aleksandrovich, Candidate of Technical Sciences, Associate Professor of the chair "Technical Service and Technology of Structural Materials", Saratov State Agrarian University named after N.I. Vavilov. Russia.

Chumakova Svetlana Valentinovna, , Candidate of Technical Sciences, Associate Professor of the chair "Mathematics and Mathematical Modeling" of the Saratov State Agrarian University named after N.I. Vavilov. Russia.

Gorbushin Pavel Aleksandrovich, Assistant of the chair "Technical Service and Technology of Structural Materials", Saratov State Agrarian University named after N.I. Vavilov. Russia.
Keywords: composite coatings; galvanic coatings; nanodispersed particles; reliability; degree of hardening; microhardness; dislocations; material structure.

The article proposes a physico-mathematical model of the mechanism of hardening of galvanic coatings by nanoscale materials. It has been established that the mechanism of hardening is most strongly influenced by structural transformations occurring in nanocomposite coatings. Based on the physical processes taking place in modified by nanoscale materials galvanic coatings, the physico-mathematical model of the mechanism of their hardening was substantiated and investigated. The presented model allows predicting the degree of hardening of nanocomposite coatings depending on the nanodispersed materials and the distance between them in the coating.

Удк 631.532.2+631.331.072.3

\section{СХЕМА ПРОЦЕССА ОБРАЗОВАНИЯ ВАЛКА ЛУКА-СЕВКА НА СФОРМИРОВАННОМ ЛОЖЕ ПРИ МЕХАНИЗИРОВАННОЙ УБОРКЕ}

\author{
СИБИРЁВ Алексей Викторович, Федеральный научный агроинженерный центр ВИМ \\ АКСЕНОВ Александр Геннадьевич, Федеральный научный агроинженерный центр ВИМ \\ дОРОХОВ Алексей Семенович, Федеральный научный агроинженерный центр ВИМ
}

Теоретически определен технологический процесс образования валка лука-севка при его механизированной уборке. Определены возможные варианты расположения луковиц, лука-севка в валке, объемы, занимаемые луковицами в валке, величина смятия объема почвы катком-ложеобразователем лукоуборочной машины, плотность почвы после ее деформации катком-ложеобразователем лукоуборочной машины.

Введение. При формировании валка лукасевка на поверхности поля лукоуборочной машиной луковицы взаимодействуют друг с другом и с поверхностью почвы [3-7]. В процессе извлечения луковиц из почвы лукоуборочная машина движется поступательно, что препятствует образованию на поверхности поля валка лука-севка большой высоты и тем самым увеличивается число поврежденных луковиц (так как в результате увеличения валка высота падения луковиц и 
величина приобретенного ими при ударе о нижележащие луковицы механического воздействия уменьшается, а количество лука-севка в слое валка увеличивается). Чрезмерному увеличению ширины валка лука-севка и тем самым предотвращению раскатывания луковиц препятствуют бортики, образованные прикатывающим катком лукоуборочной машины [5].

Цель исследования - анализ технологического процесса образования валка лука-севка при его механизированной уборке.Данная необходимость обусловлена уточнением основных размерно-массовых и физико-механических характеристиквалкалука-севка (исходя из увеличения урожайности лука-севка в результате использования высокоурожайных гибридов), являющимися входными факторами при проектировании приемно-подкапывающей части машины во второй фазе уборки лука-севка, т.е. при подборе из валков.

Методика исследований. Рассмотрим процесс образования валка лука-севка при его укладке на поверхность поля (рис. 1). Предположим, что луковицы падают с транспортера лукоуборочной машины по одной друг за другом.

Рассмотрим возможные варианты расположения луковиц лука-севка в валке. При этом необходимо принять следующие допущения:луковица представляет собой абсолютно твердое тело; луковица имеет шарообразную форму, одинаковые размеры и массу [1].

Результаты исследований. Луковицы могут принимать положения, при которых их центры тяжести находятся на взаимно перпендикулярных прямых. Наиболее устойчивым будет являться такое положение луковиц в валке, при котором занимаемая ими площадь имеет наименьшее значение. Для этого определим площадь, занимаемую луковицами при их различных положениях. Расстояние между центрами $C$ и $B$ луковиц для схем размещения, изображенных на рисунке 1 , а, в равно [7]:

$$
C_{2,4}=B_{2,4}=B_{3}=D_{\mathbf{\Omega}}\left(n_{\mathbf{B}}-1\right),
$$

где $n_{\mathrm{B}}$ - число луковиц в ряду валка, шт.

Для схемы размещения, изображенной на рис. 1, б:

$$
C_{3}=D_{\text {Л }} \cdot\left(\mathrm{n}_{\mathrm{B}}-1\right) \cdot \sin \alpha_{\text {Л }}
$$

где $\alpha_{\iota_{л}}$ - угол, между центром тяжести луковиц в валке, град.

Площадь, занимаемая луковицами по линии центров [7]:

$$
\begin{gathered}
F_{2,4}=D_{\pi}^{2}\left\{n_{\mathrm{B}}-1\right\}^{2} . \\
F_{3}=D_{\pi}^{2}\left\{n_{\mathrm{B}}-1\right\}^{2} \cdot \sin \alpha_{\sqrt{\pi}} .
\end{gathered}
$$

Площадь частиц нижнего слоя при плотной их укладке колеблется в пределах:

$$
D_{\pi}^{2}\left\{n_{\mathrm{B}}-1\right\}^{2}>F>D_{\pi}^{2}\left\{n_{\mathrm{B}}-1\right\}^{2} \cdot \sin \alpha_{]_{\pi}} .
$$

Как видно из рис. 1, луковицы верхнего слоя валка могут занимать по отношению к нижнему слою три граничных положения, при которых луковицы имеют две, три или четыре точки контакта с нижними луковицами и передают давление через эти точки. Высота горизонтальных слоев луковиц будет различной для данных положений. Определим расстояние $h_{2,3,4}$ между центрами луковиц в проекции на вертикальную плоскость, для чего проведем через центры нижних и верхних луковиц вертикальные плоскости, в результате получим:

$$
\begin{aligned}
& h_{2}=\frac{D_{\Pi}}{\sqrt{2}} . \\
& h_{3}=\frac{D_{\Pi} \sqrt{3}}{2} . \\
& h_{4}=\frac{d_{\Pi} \sqrt{2}}{\sqrt{3}} .
\end{aligned}
$$

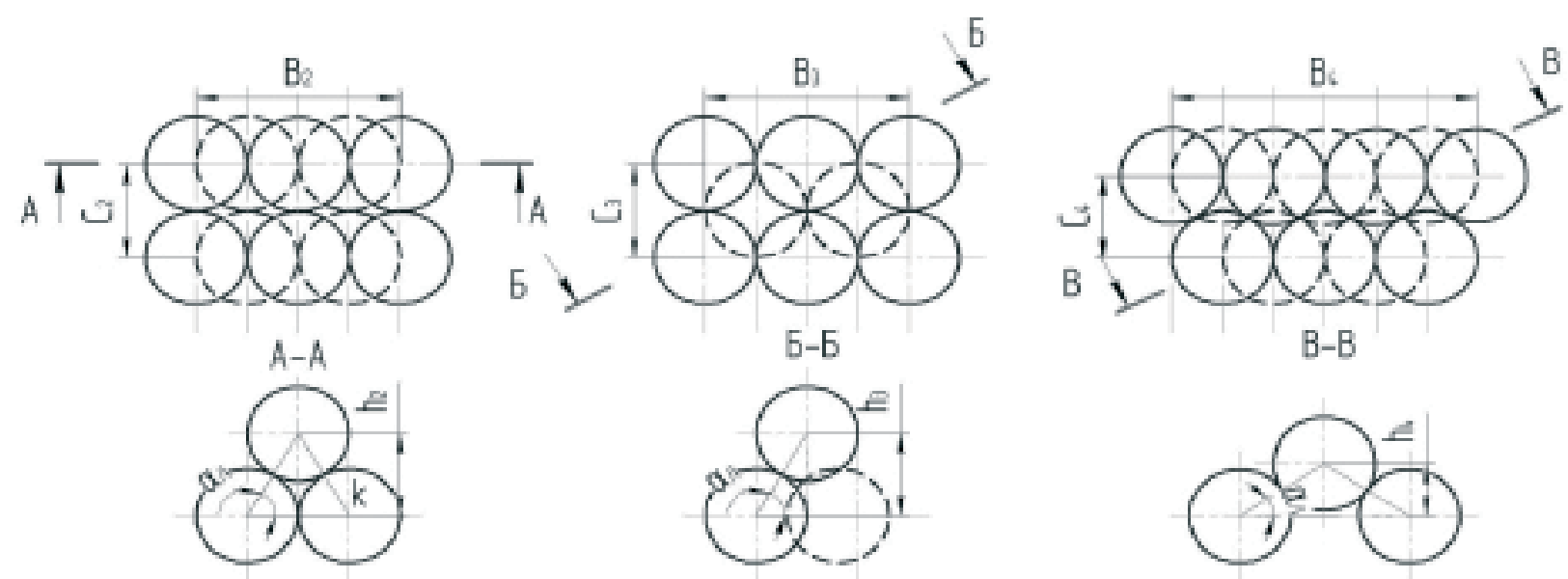


Объемы, занимаемые луковицами в валке, соответственно равны:

$$
V_{2}=F_{2} h_{2}=\frac{1}{\sqrt{2}} D_{\Omega}\left(n_{\mathrm{B}}-1\right) \cdot\left(N_{\mathrm{C}}-1\right),
$$

где $N_{\text {C }}$ - число горизонтальных слоев луковиц в валке, шт.

Таким образом, объемы $V_{2}$ и $V_{3}$ равны между собой и их значение меньше $V_{4}$. Поэтому при всевозможных внешних воздействиях луковицы будут стремиться занять положение, соответствующее объему $V_{2}$ и $V_{3}$.

Согласно рисунку 2 , величина смятия объема

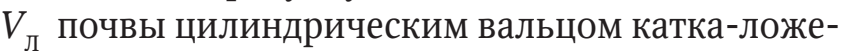
образователя лукоуборочной машины с целью предотвращения раскатывания луковиц по поверхности поля определяется по формуле

$$
V_{\boldsymbol{\Omega}}=V_{\mathrm{KABK}_{1} \mathrm{~A}_{1} \mathrm{~B}_{1}}+V_{\mathrm{ECDE}_{1} \mathrm{C}_{1} \mathrm{D}_{1}}+V_{\mathrm{ABCEA}_{1} \mathrm{~B}_{1} \mathrm{BC}_{1} \mathrm{E}_{1}},
$$

где $V_{\text {КАвК }_{1} \mathrm{~A}_{1} \mathrm{~B}_{1}-}$ объем треугольной призмы $\mathrm{KABK}_{1} \mathrm{~A}_{1} \mathrm{~B} 1, \mathrm{M}^{3} ; \mathbf{K A B K}_{1} \mathbf{A}_{1} \mathbf{B}_{1}, \mathrm{M}^{3} ; V_{\mathrm{ECDE}_{1} \mathrm{C}_{1} \mathrm{D}_{1}-}$ объем треугольной призмы $\operatorname{ECDE}_{1} \mathrm{C}_{1} \mathrm{D}_{1}, \mathbf{M}^{3}$;

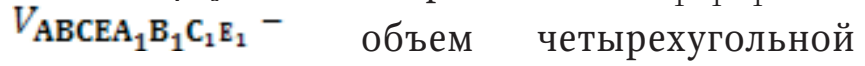
призмы $\mathrm{ABCEA} \mathrm{B}_{1} \mathrm{C}_{1} \mathrm{E}_{1}, \mathrm{M}^{3}$.

При вычислении объема $\mathbf{V}_{\boldsymbol{л}}$ смятия почвы цилиндрическим вальцом катка-ложеобразователя примем допущение, что валок лу- ка-севка является симметричным относительно осевой линии.

В результате принятого допущения следует:

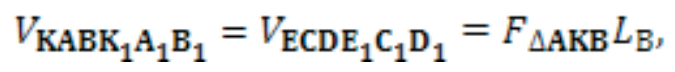

где $F_{\Delta \mathrm{AKв}}-$ площадь основания треугольной призмы $\mathrm{KABK}_{1} \mathrm{~A}_{1} \mathrm{~B}_{1}, \mathrm{M}^{3} ; \mathrm{L}_{\mathrm{B}}-$ длина валка лука-севка, м.

$$
\begin{aligned}
& \text { Площадь } F_{\triangle A K в} \text { треугольника АКВ опреде- } \\
& \text { лим по формуле } \\
& F_{\triangle \mathrm{AKB}}=\frac{1}{2} \mathrm{MB} \cdot \mathrm{MA} \text {. }
\end{aligned}
$$

Высота треугольника $M A=1,5 D_{\text {л, }}$ а величину стороны $M B$ определим:

$$
\mathrm{MB}=\sqrt{\operatorname{ctg}^{2} \alpha_{\pi}-2,25 \mathrm{D}^{2}} \text {. }
$$

Подставляя выражение (15) в (14), имеем:

$$
F_{\triangle \mathrm{AKB}}=0,75 D_{Л} \sqrt{\operatorname{ctg}^{2} \alpha_{Л}-2,25 D_{Л}^{2}} .
$$

В результате принятого допущения имеем:

$$
F_{\triangle \mathrm{AKB}}=F_{\triangle \mathrm{ECD}}=\mathbf{0 , 7 5} D_{Л} \sqrt{\operatorname{ctg}^{2} \alpha_{\Omega}-2,25 D_{Л}^{2}} .
$$

Согласно выражению (17) выражение (13) принимает следующий вид:

$V_{\mathrm{KABK}_{1} \mathrm{~A}_{1} \mathrm{~B}_{1}}=V_{\mathrm{ECDE}_{1} \mathrm{C}_{1} \mathrm{D}_{1}}=0,75 D_{\Omega} L_{\mathrm{B}} \sqrt{\operatorname{ctg}^{2} \alpha \Omega-2,25 D_{\Pi}^{2}}$.

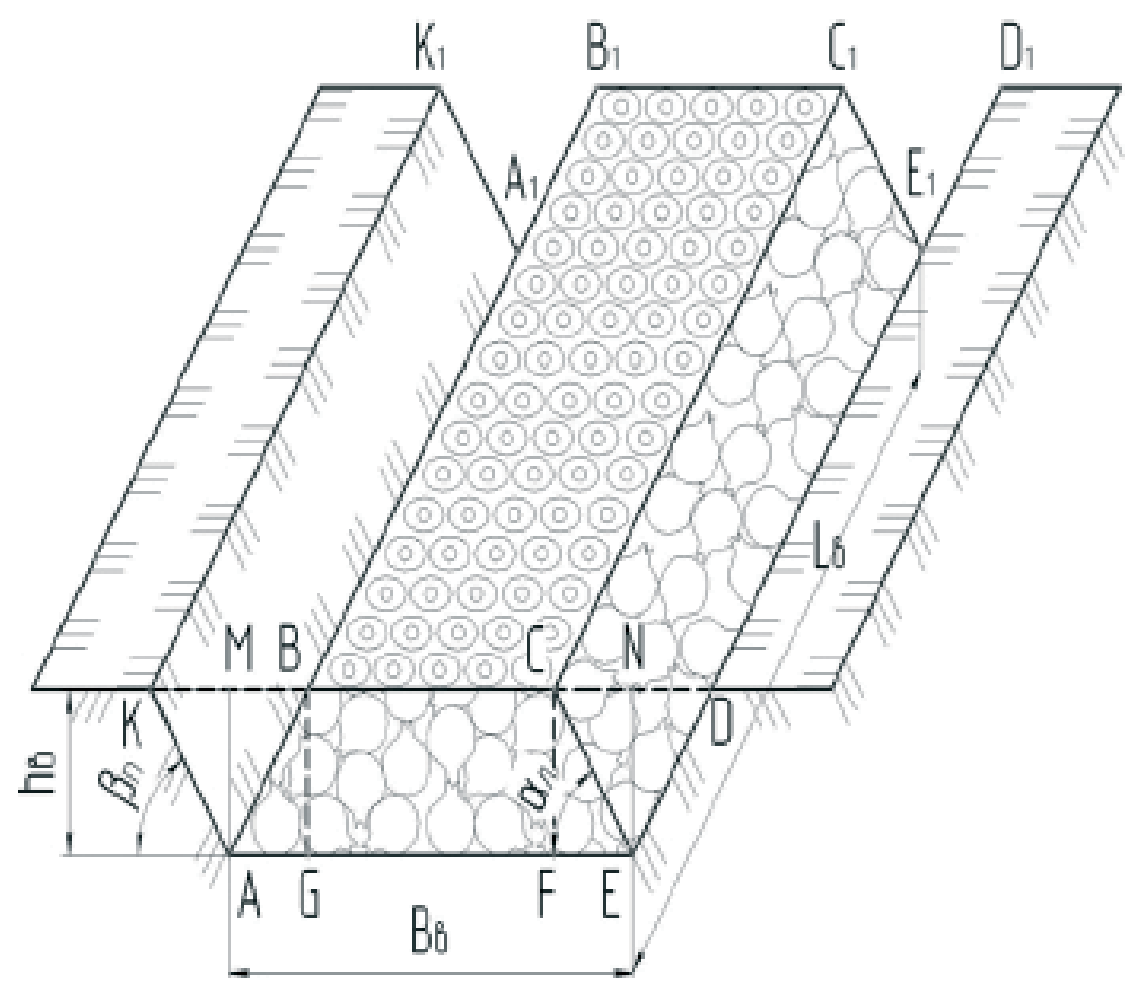


Объем валка лука-севка, уложенного на образованное ложе, определим по формуле:

$$
V_{\mathrm{ABCEA}_{1} \mathrm{~B}_{1} \mathrm{C}_{1} \mathrm{E}_{1}}=F_{\mathrm{ABCE}} L_{\mathrm{B}}
$$

где $F_{\mathrm{ABCE}}-$ площадь основания четырехугольной призмы $\mathrm{ABCEA_{1 }} \mathrm{B}_{1} \mathrm{C}_{1} \mathrm{E}_{1}, \mathrm{M}^{3}$.

Площадь $F_{A B C E}$ равнобедренной трапеции $A B C E$ определим по формуле

$$
F_{\mathrm{ABCE}}=\frac{\mathbf{B C}+\mathbf{A E}}{2} \cdot h_{\mathrm{B}} .
$$

Также площадь $F_{A B C E}$ равнобедренной трапеции $\mathrm{ABCE}$ определяется как

$$
F_{\mathrm{ABCE}}=F_{\triangle \mathrm{ABG}}+F_{\triangle \mathrm{ECF}}+F_{\mathrm{GBCF}} \text {. }
$$

Площадь $\mathbf{F}_{\triangle \mathrm{ABG}}$ треугольника $A B G$ определим по формуле

$$
F_{\triangle \mathrm{ABG}}=\frac{1}{2} \mathrm{AB} \cdot \mathrm{BG} .
$$

Высота треугольника $\mathrm{BG}=1,5 D_{\text {л }}$, а величину стороны $A B$ определим:

$$
\mathrm{AB}=\operatorname{ctg} \alpha_{\sqrt{1}}
$$

Подставляя выражение (23) в (22), имеем:

$$
F_{\triangle \mathrm{ABG}}=0,75 \mathrm{ctg} \alpha_{\pi} D_{Л} .
$$

В результате принятого допущения имеем:

$$
F_{\triangle \mathrm{ABG}}=F_{\triangle \mathrm{ECF}}=0,75 \mathrm{ctg} \alpha_{Л} D_{Л} .
$$

Площадь $P_{\mathrm{GBCF}}$ прямоугольника $\mathbf{G B C F}$ :

$$
P_{\mathrm{GBCF}}=\mathbf{B G} \cdot \mathbf{B C} \text {. }
$$
лим:

Сторону $B C$ прямоугольника $G B C F$ опреде-

$$
\mathrm{BC}=\mathrm{GF}=\mathrm{AE}-\mathrm{AG}-\mathrm{FE} .
$$

Сторона $A G$ треугольника $A B G$ :

$$
A G=\sqrt{\operatorname{ctg}^{2} \alpha_{\text {Л }}-2,25 D_{\text {л }}}
$$

С учетом выражения (28) выражение (27) примет следующий вид:

$$
\mathrm{BC}=\mathrm{GF}=\mathrm{B}_{\text {тР }}-2 \sqrt{\operatorname{ctg}^{2} \alpha_{л}-2,25 \mathrm{D}_{\text {л }}}
$$

Площадь $S_{G B C F}$ прямоугольника GBCF:

$$
F_{G B C F}=D_{Л} \cdot\left(B_{T P}-2 \sqrt{\operatorname{ctg}^{2} \alpha_{Л}-2,25 D_{Л}}\right) .
$$

Площадь $F_{A B C E}$ равнобедренной трапеции $A B C E$ равна:

$$
\mathrm{F}_{\mathrm{ABCE}}=1,5 \operatorname{ctg} \alpha_{Л} \cdot \mathrm{D}_{\pi}+\mathrm{D}_{\pi} \cdot\left(\mathrm{B}_{\mathrm{TP}}-2 \sqrt{\operatorname{ctg}^{2} \alpha_{Л}-2,25 D_{Л}}\right)
$$

Таким образом, объем $\mathrm{V}_{\text {л }}$ почвы, необходимый для смятия цилиндрическим вальцом каткаложеобразователя с целью укладки лука-севка на образованное ложе для предотвращения процесса раскатывания луковиц равен:

$$
\mathrm{V}_{\text {Л }}=\left[1,5 \operatorname{ctg} \alpha_{\text {Л }} \cdot D_{\text {Л }}+D_{Л} \cdot\left(\mathrm{B}_{\mathrm{TP}}-2 \sqrt{\operatorname{ctg}^{2} \alpha_{Л}-2,25 D_{Л}}\right)\right] \cdot \mathrm{L}_{\mathrm{B}} .
$$

Плотность $\rho_{1}$ почвы до прохода каткаложеобразователя лукоуборочной машины определяется по формуле [8, 9, 10]:

$$
\rho_{1}=\frac{m_{1}}{V_{1}},
$$

где $\rho_{1}-$ плотность почвы до ее деформации катком-ложеобразователем лукоуборочной машины, кг $/ \mathrm{M}^{3} ; \quad m_{1}$ масса почвы до ее деформации катком-ложеобразователем лукоуборочной машины, кг; $V_{1}$ - объем почвы до ее деформации катком-ложеобразователем лукоуборочной машины, м $^{3}$.

Плотность $\rho_{2}$ почвы образованного ложа определяется по формуле [10]:

$$
\rho_{\mathbf{2}}=\frac{m_{2}}{V_{2}},
$$

где $\rho_{\mathbf{2}}-$ плотность почвы после ее деформации катком-ложеобразователем лукоуборочной машины, кг $/ \mathrm{M}^{3} ; m_{\mathbf{2}}-$ масса почвы после ее деформации

катком-ложеобразователем лукоуборочной машины, кг; $V_{2}$ - объем почвы после ее деформации катком-ложеобразователем лукоуборочной машины, $\mathrm{M}^{3}$.

Так как масса почвы как до, так и после прохода катка-ложеобразователя

$$
m_{1}=m_{2} \text {, }
$$

то плотность $\rho_{\mathbf{2}}$ после преобразования выражений (33) и

(34):

$$
\rho_{2}=\frac{\rho_{1} V_{1}}{V_{2}} \text {. }
$$

Для определения объема $V_{1}$ почвы до ее деформации катком-ложеобразователем лукоуборочной машины рассмотрим рис. 3.

Профиль поверхности участка поля после 
извлечения лука-севка из почвы до деформации его катком-ложеобразователем представляет собой четырехгранную призму $\mathrm{A}_{2} \mathrm{~B}_{2} \mathrm{C}_{2} \mathrm{E}_{2} \mathrm{~A}_{3} \mathrm{~B}_{3} \mathrm{C}_{3} \mathrm{E}_{3}$.

При этом объем почвы $V_{\mathbf{1}}$ :

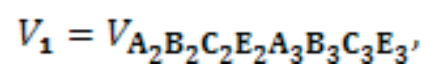

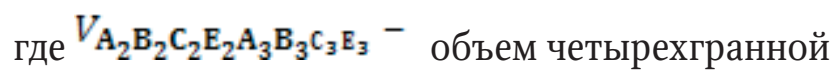
призмы $\mathrm{A}_{2} \mathrm{~B}_{2} \mathrm{C}_{2} \mathrm{E}_{2} \mathrm{~A}_{3} \mathrm{~B}_{3} \mathrm{C}_{3} \mathrm{E}_{3}, \mathrm{M}^{3}$.

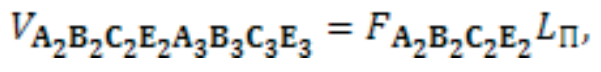

где $F A_{2} B_{2} C_{2} E_{2}$ - площадь равнобедренной трапеции $A_{2} B_{2} C_{2} E_{2} \mathrm{M}^{2} ; L_{I^{-}}$длина поверхности взрыхленного участка почвы, м.

$$
F_{\mathrm{A}_{2} \mathrm{~B}_{2} \mathrm{C}_{2} \mathrm{E}_{2}}=\frac{\mathbf{B}_{2} \mathrm{C}_{2}+\mathrm{A}_{2} \mathrm{E}_{2}}{2} \cdot h_{\Pi},
$$

где $\mathrm{h}_{\text {п }}$ - глубина взрыхленного лемехами слоя почвы, м.

$$
F_{\mathrm{A}_{2} \mathrm{~B}_{2} \mathrm{C}_{2} \mathrm{E}_{2}}=F_{\Delta \mathrm{A}_{2} \mathrm{~B}_{2} \mathrm{G}_{2}}+F_{\Delta \mathrm{E}_{2} \mathrm{C}_{2} \mathrm{~F}_{2}}+F_{\mathrm{G}_{2} \mathrm{~B}_{2} \mathrm{C}_{2} \mathrm{~F}_{2}} \text {. }
$$

Площадь $F_{\Delta \mathrm{A}_{2} \mathrm{~B}_{2} \mathrm{G}_{2}}$ треугольника $\mathrm{A}_{2} \mathrm{~B}_{2} \mathrm{G}_{2}$ определим по формуле

$$
F_{\Delta A_{2} B_{2} G_{2}}=\frac{1}{2} A_{2} B_{2} \cdot \mathbf{B}_{2} G_{2} \text {. }
$$

Высота треугольника $B_{2} G_{2}=h_{\Pi}$, а величину стороны $\mathbf{A}_{2} \mathbf{B}_{2}$

определим:

$$
A_{2} B_{2}=\operatorname{ctg} \beta_{\Pi} .
$$

Подставляя выражение (42) в (41), получаем:

$$
F_{\Delta \mathrm{A}_{2} \mathrm{~B}_{2} \mathrm{G}_{2}}=\frac{1}{2} \operatorname{ctg} \beta_{\Pi} h_{\Pi} \text {. }
$$

В результате принятого допущения имеем:

$$
F_{\Delta \mathrm{A}_{2} \mathrm{~B}_{2} \mathrm{G}_{2}}=F_{\Delta \mathrm{E}_{2} \mathrm{C}_{2} \mathrm{~F}_{2}}=\frac{1}{2} \operatorname{ctg} \beta_{\Pi} h_{\Pi} \text {. }
$$

Площадь $F_{\mathrm{G}_{2} \mathrm{~B}_{2} \mathrm{C}_{2} \mathrm{~F}_{2}}$ прямоугольника $\mathrm{G}_{2} \mathrm{~B}_{2} \mathrm{C}_{2} \mathrm{~F}_{2}$ :

$$
F_{G_{2} B_{2} C_{2} F_{2}}=G_{2} B_{2} \cdot B_{2} C_{2} .
$$
делим:

Сторону $B_{2} C_{2}$ прямоугольника $G_{2} B_{2} C_{2} F_{2}$ опре-

$$
\mathrm{B}_{2} \mathrm{C}_{2}=\mathrm{G}_{2} \mathrm{~F}_{2}=\mathrm{A}_{2} \mathrm{E}_{2}-\mathrm{A}_{2} \mathrm{G}_{2}-\mathrm{F}_{2} \mathrm{E}_{2} \text {. }
$$

Сторона $\mathbf{A}_{\mathbf{2}} \mathbf{G}_{2}$ треугольника $\mathbf{A}_{\mathbf{2}} \mathbf{B}_{\mathbf{2}} \mathbf{G}_{2}$ :

$$
\mathbf{A}_{2} \mathbf{G}_{2}=\sqrt{\operatorname{ctg}^{2} \beta_{\Pi}-h^{2} \Pi}
$$

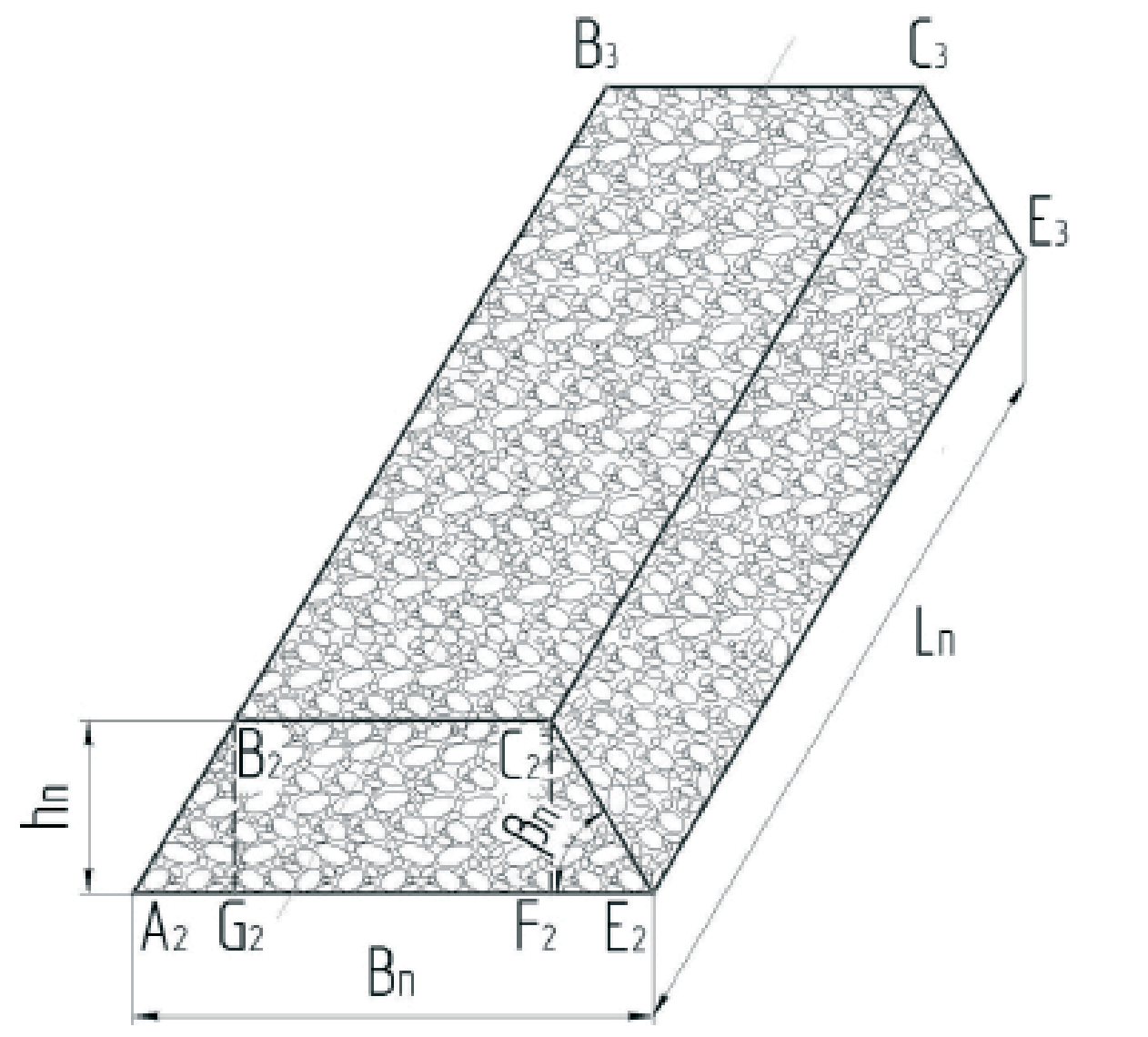

Рис. 3. К определению объема почвы до деформации катком-ложеобразователем лукоуборочной машины 
С учетом выражения (47) выражение (46) примет следующий вид:

$$
B_{2} C_{2}=G_{2} F_{2}=B_{\Pi}-2 \sqrt{\operatorname{ctg}^{2} \beta_{\Pi}-h_{2 \Pi}}
$$

Площадь
$\mathbf{G}_{2} \mathbf{B}_{2} \mathbf{C}_{2} \mathrm{~F}_{2}:$$F_{\mathrm{G}_{2} \mathrm{~B}_{2} \mathrm{C}_{2} \mathrm{~F}_{2}}$ прямоугольника

$$
\mathrm{F}_{\mathrm{G}_{2} \mathrm{~B}_{2} \mathrm{C}_{2} \mathrm{~F}_{2}}=h_{\Pi} \cdot\left(B_{\Pi}-2 \sqrt{\operatorname{ctg}^{2} \beta_{\Pi}-h^{2} \Pi}\right) ;
$$

$$
\text { Площадь } \quad F_{\mathrm{A}_{2} \mathrm{~B}_{2} \mathrm{C}_{2} \mathrm{E}_{2}}
$$

равнобедренной

трапеции $A_{2} B_{2} C_{2} E_{2}$ равна:

$$
\mathrm{F}_{\mathrm{A}_{2} \mathrm{~B}_{2} \mathrm{C}_{2} \mathrm{E}_{2}}=\operatorname{ctg} \beta_{\Pi} \cdot h_{\Pi}+h_{\Pi} \cdot\left(B_{\Pi}-2 \sqrt{\operatorname{ctg}^{2} \beta_{\Pi}-\mathrm{h}^{2}{ }_{\Pi}}\right) ;
$$

Таким образом:

$$
\begin{aligned}
& \mathrm{V}_{\mathrm{A}_{2} \mathrm{~B}_{2} \mathrm{C}_{2} \mathrm{E}_{2} \mathrm{~A}_{3} \mathrm{~B}_{3} \mathrm{C}_{3} \mathrm{~F}_{3}}=\operatorname{ctg} \beta_{\Pi} \cdot \mathrm{h}_{\Pi}+\mathrm{h}_{\Pi} \times \\
& \times\left(B_{\Pi}-2 \sqrt{\operatorname{ctg}^{2} \beta_{\Pi}-h^{2} \Pi}\right) \cdot L_{\Pi} \\
& \rho_{\mathbf{2}}=\frac{\rho_{1} \operatorname{ctg} \beta_{\Pi} h_{\Pi}+h_{\Pi} \llbracket\left(F \prod_{\Pi}-2 \sqrt{\operatorname{ctg}^{2} \beta_{\Pi}-h^{2} \Pi}\right) \cdot L_{\Pi}}{\left[1,5 \operatorname{ctg} \alpha_{\Pi} d_{\Pi}+d_{\Pi} \llbracket\left(F \sum_{\mathrm{TP}}-2 \sqrt{\operatorname{ctg}^{2} \alpha_{\Pi}-2,25 d_{\Pi}}\right)\right] \cdot L_{\mathbf{B}}} .
\end{aligned}
$$

Заключение. Определены величина смятия объема $V_{\text {л }}$ почвы, цилиндрическим вальцом катка-ложеобразователя лукоуборочной машины (32), которая препятствует раскатыванию луковиц по поверхности поля, плотность почвы $\rho_{\mathbf{2}}$

(52) после ее деформации катком-ложеобразователем лукоуборочной машины, являющимися входными факторами при обосновании конструктивных параметров приемно-подкапывающей части машины для подбора лука-севка из валков, а именно толщины, длины и ширины лемеха.

\section{СПИСОК ЛИТЕРАТУРЫ}

1. Аксенов А.Г., Сибирёв А.В. Исследование размерно-массовых характеристик лука-севка гибрида «Геркулес F1» // Вестник Казанского ГАУ. - 2016. № 2 (40). - C.5-10.

2. Бузенков Г.М., Ма С.А. Машины для посева сельскохозяйственных. - М.: Машиностроение, 1987. - 272 с.

3. Ларюшин А.М. Энергосберегающие технологии и технические средства для уборки лука: дис. ... д-ра техн. наук. - Пенза, 2010. - 426 с.

4. Машинная технология производства лука: Монография / Я.П. Лобачевский[и др.],. - М., 2016. $168 \mathrm{c}$.

5. Протасов А.А. Совершенствование технологических процессов и технических средств для уборки лука: дис. ... д-ра техн. наук. - Саратов, 2005. - 355 c.

6. Рейнгарт Э.С. Обоснование параметров и разработка машин для уборки корнеплодов и лука: дис. ... д-ра техн. наук. - М., 1995. - 38 с.

7. Сорокин А.А. Теория и расчет картофелеуборочных машин. - М.: ВИМ, 2006. - 159 с.

8. Сибирёв А.В., Аксенов А.Г., Емельянов П.А. Полевые исследования катка-ложеобразователя машины для уборки лука // Тракторы и сельхозмашины. - 2017. - № 8. - С. 15-21.

9.Сибирёв А.В., Аксенов А.Г. Практические предпосылки к повышению качества работы технических средств для уборки лука-севка // Стратегические ориентиры инновационного развития АПК в современных экономических условиях: Междунар. науч.-практ. конф. - Волгоград, 2016. - С. 23-25.

10.Сибирёв А.В.,АксеновА.Г., Емельянов П.А. Каток-ложеобразователь машины для уборки лука // Инновационные идеи молодых исследователей для АПК России: сб. материалов Всерос.науч.-практ. конф. - Т. II. - Пенза: РИО ПГСХА, 2017. - С. $156-$ 160.

Сибирёв Алексей Викторович, канд. техн. наук, старший научный сотрудник, Федеральный научный агроинженерный центр ВИМ. Россия.

Аксенов Александр Геннадьевич, канд. техн. наук, Федеральный научный агроинженерный центр ВИМ. Россия.

Дорохов Алексей Семенович, д-р техн. наук, иленкорреспондент РАН, Федеральный научный агроинженерный чентр ВИМ. Россия.

109428, г. Москва, 1-й Институтский проезд, 5.

Тел.: (499) 174-89-11.

Ключевые слова: валок; лук-севок; объем луковиц; величина смятия; плотность почвы.

\section{INFLUENCE OF THE FOREST BELT AND RELIEF ON THE FORMATION OF SOIL CONSISTENCY DENSITY}

Sibiriev Aleksey Viktorovich, Candidate of Technical Sciences, Senior Researcher, Federal State Scientific Agroengineering Center VIM. Russia.

Aksenov Alexander Gennadievich, Candidate of Technical Sciences, Federal State Scientific Agroengineering Center VIM. Russia.

Dorokhov Alexei Semenovich, Doctor of Technical Sciences, Corresponding Member of the Russian Academy of Sciences, Federal Research Agroengineering Center VIM. Russia.
Keywords: roll; onion-sowing; bulb volume; amount of crushing; soil density.

The technological process of the formation of the onionsowing roller during its mechanized harvesting is theoretically determined. Possible variants of the onion-seed placement in the roll are determined, the volumes occupied by the bulbs in the roll, the amount of crushing of the soil volume by the roller-looser of the harvesting machine, the density of the soil after its deformation by the roller-leader of the harvesting machine. 